\title{
Conservação in vitro de germoplasma indexado de três cultivares de amarílis (Hippeastrum Herb.) $)^{(1)}$
}

\author{
LINCOLN AMARAL (2); RENATO FERRAZ DE ARRUDA VEIGA ${ }^{(2)}$; ANTONIO FERNANDO CAETANO TOMBOLATO ${ }^{(2,3)}$; WILSON \\ BARBOSA $^{(2,3)}$ e ARMANDO CONAGIN ${ }^{(2)}$
}

\section{RESUMO}

Pesquisaram-se as os efeitos das concentrações de 10, 20, 30 e $40 \mathrm{~g} \mathrm{~L}^{-1}$ de sacarose, adicionadas à solução salina MS de Murashige e Skoog (1962) a 50 e $100 \%$ e das temperaturas em sala de crescimento de $18{ }^{\circ} \mathrm{C}$ e $25^{\circ} \mathrm{C}$, na conservação in vitro de três acessos do BAG-amarílis (Hippeastrum Herb.), do Instituto Agronômico (IAC). Os ápices caulinares de 'Apple Blossom', 'Red Lion' e 'Orange Souvereign', contendo 2 primórdios foliares, foram extraídos de bulbos e submetidos a $37^{\circ} \mathrm{C}$ por 40 dias, para efeito de eleiminação de virus. Efetuaram-se análises de partículas virais de folhas das três cultivares cultivadas em campo e in vitro. Empregou-se o delineamento inteiramente casualizado, em esquema fatorial $2 \times 3 \times 2$, composto de 12 tratamentos, 10 repetições e 1 explante por parcela. Verificou-se que a associação da termoterapia com a cultura in vitro reduziu a presença de partículas virais em 70, 65 e 55\% em 'Orange Souvereign', 'Red Lion' e 'Apple Blossom', respectivamente. Explantes das três cultivares de amarílis apresentaram menor desenvolvimento quando cultivados no meio de cultura MS contendo a metade da concentração de sais, acrescido de $10 \mathrm{~g} \mathrm{~L}^{-1}$ de sacarose e incubado a $18^{\circ} \mathrm{C}$, mantendo-se viáveis por 90 dias. Nessas condições, os explantes desenvolveram, em média, 1 bulbilho com 2,2; 2,0 e 2,3 folhas de 32,5; 27,8 e 25,8 cm de comprimento; 1,$7 ; 2,3$ e 2,0 raízes de 20,5; 16,8 e 18,2 cm e massa fresca de 3,9;3,4 3,1g, respectivamente, para 'Apple Blossom', 'Red Lion' e 'Orange Souvereign'.

Palavras-chave: termoterapia, vírus, sacarose, temperatura, Hippeastrum Herb.

\section{ABSTRACT \\ In vitro germplasm conservation of three indexed amaryllis cultivars (Hippeastrum Herb.)}

This work researched the effects of the $10,20,30$ and $40 \mathrm{~g} \mathrm{~L}^{-1}$ sucrose concentration, added to MS nutrients solution of Murashige and Skoog (1962), at 50 and $100 \%$, and those of the temperatures of a growing room at $18^{\circ} \mathrm{C}$ and $25^{\circ} \mathrm{C}$, in the in vitro conservation in three BAG-amaryllis accesses (Hippeastrum Herb.), of Instituto Agronômico (IAC). The stalk terminal buds of 'Apple Blossom', 'Red Lion' and 'Orange Sovereign', containing 02 primordial foliages, were extracted from bulbs, which were treated with thermotherapy at $37^{\circ} \mathrm{C}$ for 40 days. Analyses of viral particles from the three cultivars leaves, cultivated in field and in vitro, were carried out. The experimental setting adopted was entirely casual, in a factorial scheme of $2 \times 3 \times 2$, consisting of 12 treatments, 10 repetitions and 01 explant per sample. It was noticed that the association of thermo therapy with the in vitro culture reduced the presence of viral particles by 70, 65 and 55\% for 'Orange Sovereign', 'Red Lion' and 'Apple Blossom', respectively. Explants from the three amaryllis cultivars reached the smallest development when cultivated in MS medium (50\%), to which was added 10 $\mathrm{g} \mathrm{L}^{-1}$ of sucrose, and which was incubated at $18^{\circ} \mathrm{C}$, keeping their viability for at least 90 days. On these conditions, the explants developed, on average, 01 bulb with 2,2;2,0 and 2,3 leaves 32,5; 27,8 and 25,8 cm long; 1,7; 2,3 and 2,0 roots of 20,5, 16,8 and 18,2 cm and fresh mass of 3,9; 3,4 and 3,1g, for 'Apple Blossom', 'Red Lion' and 'Orange Sovereign', respectively.

Key words: thermotherapy, virus, sucrose, temperature

\footnotetext{
(1) Parte da Dissertação de Mestrado do primeiro autor, apresentada no Instituto Agronômico (IAC), na área de concentração: Melhoramento Genético Vegetal, do Programa de Pós-Graduação em Agricultura Tropical e Subtropical. Recebido para publicação em 27/10/2006 e aceito em 10/10/2007.

(2) Instituto Agronômico (IAC) - Caixa Postal 28 - 13001-970 - Campinas (SP).

(3) Bolsista CNPq (Produtividade em Pesquisa)
} 


\section{INTRODUÇÃO}

O amarílis (Hippeastrum Herb.) é uma Amaryllidaceae nativa das Américas do Sul e Central, distribuída desde a Argentina até o México (DUTILH, 1987). Mesmo havendo 40 espécies nativas de amarílis no Brasil, há carência de acessos em bancos ativos de germoplasma para suprir programas de melhoramento genético e intercâmbio científico.

A conservação dos recursos genéticos vegetais, frente ao atual cenário de acelerada destruição ambiental, é hoje uma demanda de interesse global. Dessa forma, é imperativo priorizar estratégias para preservar os recursos genéticos, bem como pesquisar novas técnicas de conservação de espécies nativas. A conservação de germoplasma in vitro tem diversas vantagens em relação à conservação no campo, tais como: menor risco de perda do germoplasma, maior qualidade fitossanitária, redução no custo de manutenção, rápida multiplicação e armazenamento, menor necessidade de espaço, disponibilidade imediata para propagação e facilidade de intercâmbio (DORION et al., 1991). A utilização de retardantes de crescimento, reguladores osmóticos e hormonais, redução da temperatura de incubação e da concentração de sais e da sacarose do meio MS, podem reduzir o custo de manutenção das coleções in vitro, diminuindo-se a necessidade de subcultivos constantes, com economia de pessoal, equipamentos e insumos. A redução da temperatura nas salas de crescimento, aliada à diminuição na concentração dos sais e de sacarose do meio MS, têm sido estratégias que, utilizadas conjuntamente, têm possibilitado sucesso no estabelecimento das condições favoráveis ao desenvolvimento mínimo in vitro em várias culturas (DODDS e ROBERTS, 1993). Os reguladores osmóticos podem reduzir a viabilidade dos explantes, além de também estarem relacionados com a incidência de instabilidade genética ao material micropropagado (CHARRIER et al., 1991).

Para se conservar adequadamente qualquer acesso vegetal, é desejável que os mesmos estejam livres de patógenos. No Brasil, há três tipos principais de vírus que afetam a cultura do amarílis. O mais freqüente, que chega a infectar até $100 \%$ das plantas no campo, é o vírus do mosaico do Hippeastrum (Hippeastrum mosaic potyvirus - HiMV). No campo, o controle dessa virose é quase impossível, especialmente devido à sua presença em plantas hospedeiras. As medidas profiláticas mais comumente adotadas consistem no combate contínuo aos insetos vetores e na eliminação total das plantas com sintomas. O Nerine latent carlavirus (NeLV) ocorre em Hippeastrum, freqüentemente associado ao HiMV. Embora nem sempre expressem sintomas evidentes, os danos provocados pelo NeLV prejudicam sensivelmente a qualidade da produção (LOEBENSTEIN et al., 1995). Em amarílis, o vírus vira cabeça do tomateiro (Tomato spotted wilt virus - TSWV) é de ocorrência esporádica e induz lesões cloróticas nas folhas. Mesmo não sendo muito freqüente, esse vírus provoca grandes perdas ao cultivo de Hippeastrum (CHO et al., 1986). De acordo com BAPAT e NARAYANASWANY (1976), a aplicação das técnicas de cultura de ápices caulinares em amarílis iniciou-se em 1972. Essa técnica permite a produção de material com alta qualidade fitossanitária (MORELe MARTIN, 1952). Outras técnicas têm sido associadas à cultura de ápices caulinares, como a termoterapia, para aumentar a eficiência no processo de eliminação de vírus (CONCI e NOME, 1991).

Objetivando a conservação in vitro de germoplasma de amarílis, pesquisaram-se neste trabalho meios de cultura, destituídos de reguladores de crescimento, temperaturas diferenciadas em sala de crescimento e a limpeza fitossanitária por associação da termoterapia com a cultura de ápices caulinares.

\section{MATERIALEMÉTODOS}

Vinte bulbos de cada uma das cultivares: Apple Blossom, Orange Souvereign e Red Lion, após tratamento a $37^{\circ} \mathrm{C}$ em câmara termostática por 40 dias, foram dissecados extraindo-se os ápices caulinares de $5 \mathrm{~mm}$ de comprimento contendo 2 primórdios foliares (TOMBOLATO et al., 1998). Objetivando aumentar a quantidade desse material in vitro, cultivaram-se os explantes em tubos de ensaio contendo a solução salina de MURASHIGE e SKOOG (1962), suplementada com mio-inositol $100 \mathrm{mg} \mathrm{L}^{-1} ; 2,0 \mathrm{mg} \mathrm{L}^{-1} \mathrm{de}$ glicina; $30 \mathrm{~g} \mathrm{~L}^{-1}$ de sacarose; $2,5 \mathrm{mg} \mathrm{L}^{-1}$ de ácido 3indolacético (AIA) e $10 \mathrm{mg} \mathrm{L}^{-1}$ de 6-benzilaminopurina (6BAP). O meio foi solidificado com $6,2 \mathrm{~g} \mathrm{~L}^{-1}$ de ágar e o $\mathrm{pH}$ ajustado para 6,0 antes da esterilização em autoclave. $\mathrm{O}$ material permaneceu em sala de crescimento por 60 dias, sob fotoperíodo de 16 horas (luz fria, branca de 2.500 lux) e temperatura de $25^{\circ} \pm 2{ }^{\circ} \mathrm{C}$.

A exemplo das plantas cultivadas no campo, extraíram-se segmentos foliares de $1 \mathrm{~cm}^{2}$ de plantas micropropagadas, para análise de partículas virais. Para diagnose viral, utilizou-se o microscópio eletrônico de transmissão (MET), por meio da técnica leaf-dip.

Para os testes de conservação in vitro, selecionaram-se 140 explantes livres de vírus, de cada cultivar, os quais foram cultivados em diferentes meios de cultura e temperaturas de sala de crescimento. Utilizaramse a solução salina MS a $100 \%$ e 50\%, sacarose a 10, 20 e $40 \mathrm{~g} \mathrm{~L}^{-1}$ e temperatura de incubação de $18^{\circ} \mathrm{C}$ e $25^{\circ} \mathrm{C}$, em câmara de cultivo. Adotaram-se dois tratamentos controles, totalizando 14 tratamentos de conservação por cultivar, com dez repetições por tratamento e uma planta por parcela. O delineamento experimental foi o inteiramente casualizado, com os tratamentos dispostos em esquema fatorial 2 x $3 \mathrm{x}$ 2. Para análise estatística, realizou-se a análise geral da variância, sendo as médias dos tratamentos comparadas pelos testes "t" e de Tukey a 5\% de probabilidade. Por meio de análise fatorial, determinou-se a influência dos tratamentos na composição da massa fresca das plantas in vitro. Após 90 dias avaliou-se o número e o comprimento médio ( $\mathrm{mm}$ ) de folhas e raízes, o número de bulbilhos e a massa fresca $(\mathrm{g})$ das plantas in vitro e adotou-se o critério "nota" de 1 a 10 para a análise, sendo que cada número da escala equivalente a aproximadamente $10 \mathrm{~mm}$ do 
comprimento total da planta (soma do comprimento da maior folha ao comprimento da maior raiz).

\section{RESULTADOS E DISCUSSÃO}

As folhas primárias das 20 amostras de cada cultivar, analisadas ao microscópio eletrônico de transmissão, tiveram resultado positivo para presença de partículas virais. Visualizaram-se, no material coletado no campo, partículas virais alongada-flexuosas típicas de Carlavirus (provavelmente Nerine latent carlavirus - NeLV) e ou espécies de Potyviridae (provavelmente Hippeastrum mosaic potyvirus - HiMV), indicando contaminação em todas as matrizes analisadas. Tais resultados justificaram plenamente a iniciativa de se realizar a conservação in vitro de germoplasma de amarílis a partir de acessos indexados.

Esses resultados corroboram a observação de QUAK (1977), de que provavelmente todas as espécies propagadas vegetativamente são infectadas por uma ou mais espécies de vírus, quando se encontram no campo, principalmente os latentes, que são de difícil identificação, como é o caso do Nerine latent carlavirus. Após o tratamento termoterápico, associado à cultura in vitro dos ápices caulinares, foi observada uma redução da presença de vírus em 55\% em 'Apple Blossom', 65\% em 'Red Lion' e $70 \%$ em 'Orange Souvereign'. Mesmo havendo relativa eficiência, acredita-se que haja necessidade de novas análises em folhas adultas dessas cultivares. Isto porque, durante a organogênese in vitro, o material está em intenso processo de divisão celular, podendo conter traços de partículas virais não detectáveis ao microscópio eletrônico (BALASINGAM et al.,1988).

Conforme dados da tabela 1 , verifica-se tendência de maior potencial de conservação em meio MS $50 \%$ e concentração de sacarose de $10 \mathrm{~g} \mathrm{~L}^{-1}$, nas três cultivares pesquisadas. A temperatura de $25^{\circ} \mathrm{C}$ demonstrou menor potencial de conservação nas três cultivares. A regressão entre "massa fresca" e "nota" foi altamente significativa ( $p<0,0001)$, demonstrando elevada correlação entre as duas variáveis. A análise geral da variância (tabela 2 ) indicou um valor de $F$ altamente significativo ( $a<0,0001$ $=0,01 \%$ ). Observou-se que, as diferenças entre tratamentos e cultivares na composição das médias da massa fresca, não são casuais, exercendo efeito expressivo entre si. Os resultados do teste de Tukey apontaram diferença altamente significativa $(\mathrm{a}<0,0001=0,01 \%)$ entre as médias da massa fresca das cultivares. Entre 'Red Lion' e 'Orange Souvereign', o valor de " $p$ ” para as médias da massa fresca foi de $0.0546(a=0,0546=5,46 \%)$. Apesar de próximo da significância de 5\%, nesse caso, não é possível rejeitar a hipótese de igualdade entre essas duas cultivares, que não diferiram entre si e se comportaram de forma homogênea. Assim, 'Apple Blossom' (média geral da massa fresca de 6,64 g), teve menor potencial de conservação in vitro do que 'Red Lion' (média geral da massa fresca de $5,87 \mathrm{~g}$ ) e 'Orange Souvereign' (média geral da massa fresca de $5,72 \mathrm{~g}$ ). Por meio de análise fatorial avaliaram-se as interações e efeitos nos tratamentos de um a doze (tabela 3). A fim de uniformizar o número de parcelas, utilizaram-se apenas sete repetições por tratamento, descartando-se as parcelas perdidas.

Houve efeito altamente significativo $(\mathrm{F}<0,0001)$ das variáveis "cultivar", "sacarose", "temperatura" e "meio MS" sobre a composição das médias da massa fresca; demonstrando que tais variáveis influenciaram a conservação in vitro de amarílis. A interação entre "cultivares" e "sacarose" $(\mathrm{F}=2,11 \%)$ foi significativa a 5\% de probabilidade. As variáveis, "sacarose" e "temperatura" $(\mathrm{F}<0,0001)$, "sacarose" e "meio" ( $\mathrm{F}<0,0001)$, "temperatura" e "meio" $(F<0,0001)$ e "cultivares" e "temperatura" $(F=$ $0,19 \%$ ), interagiram entre si de forma altamente significativa. As variáveis "cultivares" e "meio" responderam de forma homogênea e não diferiram entre si na composição das médias da massa fresca nos tratamentos de um a doze.

O teste " $\mathrm{t}$ " posicionou as cultivares em grupos distintos (grupos A, B e C), demonstrando efeito significativo entre si. Ao se excluírem as parcelas perdidas por contaminação, apesar de o número de repetições da análise ter sido diminuído de dez para sete, permitiu-se maior homogeneidade dos dados (tabela 4). Com isso, verificou-se influência significativa de cada cultivar na composição das médias da massa fresca das plantas in vitro (6,05 g em 'Apple Blossom'; 5,18 g em 'Red Lion' e $4,98 \mathrm{~g} \mathrm{em}$ 'Orange Souvereign'). Como cada cultivar exerceu efeito próprio na produção (massa fresca) das plantas in vitro, elas comportaram-se de maneira distinta na conservação in vitro. 'Orande Souvereign' teve o melhor potencial de conservação. Já 'Red Lion' proporcionou resultado intermediário e 'Apple Blossom' demonstrou menor capacidade para conservação, em períodos mais prolongados. Portanto, ao trabalhar com bancos de germoplasma de Hippeastrum, recomenda-se planejar as condições de conservação in vitro mais adequadas para cada cultivar, de acordo com o período de tempo que se espera conservar o material e os objetivos da pesquisa.

As concentrações de sacarose de 20 e $40 \mathrm{~g} \mathrm{~L}^{-1}$, ambas pertencentes ao grupo A do teste " $t$ ", tiveram resultados semelhantes, diferindo significativamente de $10 \mathrm{~g} \mathrm{~L}^{-1}$ (grupo B). A temperatura de $18^{\circ} \mathrm{Ce} 25^{\circ} \mathrm{C}$ e do meio MS completo e incompleto foram também classificados em grupos distintos do teste " $\mathrm{t}$ ", indicando efeito diferencial na composição das médias da massa fresca. A padronização dos dados permitiu indicar as condições fisiológicas mais propícias à conservação in vitro para as três cultivares testadas: concentração de $10 \mathrm{~g} \mathrm{~L}^{-1}$ de sacarose, temperatura de incubação de $18{ }^{\circ} \mathrm{C}$ e $50 \%$ da concentração de macro e micronutrientes do meio de MURASHIGE e SKOOG (1962).

Realizou-se, por meio da análise fatorial, avaliação da interação entre as três cultivares e os 14 tratamentos de conservação, comparando-se as médias e desvios- padrão da variável massa fresca (tabela 4). Para uniformizar os dados, foram computadas apenas sete repetições por tratamento, incluindo-se os tratamentos testemunhas. A interação entre cultivares e tratamentos demonstrou-se altamente significativa $(\mathrm{F}<0,0001)$. Por meio do teste " $t$ " constatou-se diferença significativa das três cultivares entre si, sendo cada qual inserida em um grupo " $\mathrm{t}$ " específico. O teste " $\mathrm{t}$ " ordenou os tratamentos 
em 10 grupos distintos. Considerando-se todos os tratamentos de conservação in vitro, observa-se (figura 1) que o tratamento 3 (10 gramas.litro ${ }^{-1}$ de sacarose, $18^{\circ} \mathrm{C}$ e $50 \%$ de meio MS) permitiu o maior patamar de conservação in vitro das mudas micropropagadas de amarílis. Assim, como cada cultivar foi classificada em um grupo distinto do teste " $t$ " e os dados contemplam a média da massa fresca para as 3 cultivares, pode-se comprovar, quantitativamente, que esse tratamento foi o mais efetivo à conservação in vitro para as três cultivares em estudo. Os tratamentos controles do experimento (13 e 14) foram aqueles que tiveram a menor dispersão de dados e propiciaram o menor patamar de conservação in vitro. Os tratamentos intermediários entre o grupo controle e o grupo 3, caracterizaram-se por elevada dispersão dos dados. Os tratamentos 5 e 2 (grupo D do teste " $\mathrm{t}$ ") exerceram a mesma influência na conservação in vitro de amarílis, fato esse também observado entre os tratamentos 1,7 e 12.

\section{CONCLUSÕES}

1. Na micropropagação de amarílis, o meio de cultura composto da solução salina MS, suplementada com $100 \mathrm{mg} \mathrm{L}^{-1}$ de mio-inositol, 2,0 $\mathrm{mg} \mathrm{L}^{-1}$ de glicina e $30 \mathrm{~g} \mathrm{~L}^{-1} \mathrm{de}$ sacarose, sem adição de reguladores de crescimento, proporciona adequado desenvolvimento dos explantes para 'Apple Blossom', 'Red Lion' e 'Orange Souvereign';

2. A associação da termoterapia com a cultura de ápices caulinares demonstra relativa eficiência na limpeza de vírus nas três cultivares de amarílis estudadas;

3. O meio de cultura contendo a metade da concentração dos macro e micronutrientes do meio de MURASHIGE e SKOOG (1962), acrescido de $10 \mathrm{~g} \mathrm{~L}^{-1} \mathrm{de}$ sacarose, não prejudica o desenvolvimento dos explantes conservados in vitro. Associando-se esse meio de cultura à temperatura de $18{ }^{\circ} \mathrm{C}$ em sala de crescimento, os explantes reduzem o desenvolvimento vegetativo e mantêm-se viáveis por 90 dias sem a necessidade de novos subcultivos, enquanto a freqüência de sub-cultivos pelo método convencional é a cada 30 dias.

\section{REFERÊNCIAS}

BALASINGAM, G; ELLISON, N.; MILNE, K.S; FORSTER, R.L.S. Sensitive and specific detection of two filamentous viruses from nerines using cloned cDNA probes. Acta Horticulturae, Wageningen, v.234, p.267-274, 1988.

BAPAT, V.A.; NARAYANASWANY, M. Growth and organogenesis in explant tissues of Amaryllis in culture. Bulletin of the Torrey Botanical Club, Bronx, v. 103, n.2, p.53-56, 1976.
CHARRIER, A.; DEREUDDRE, J.; ENGELMANN, F. The implications of biotechnology in germplasm conservation and utilization. Crop Genetic Resources of Africa. Vol II. N.Q. Ng, P. Perrino, F. Attere, H. Zedan ed., Ibadan, Nigeria, IITA/IBPGR/UNEP/CNR, In: INTERNATIONAL CONFERENCE ON CROP GENETIC RESOURCES OF AFRICA. Nigéria, 1991. Proceedings... Nigeria, 1991, p.279-286.

CHO, J.J.; MAU; R.F.L.; GONSALVES, D.; MITCHELL, W.C. Reservoir weed host of tomato spotted wilt virus. Plant Disease, Saint Paul, v.70. 1986.

CONCI, V.C.; NOME, S.F. Vírus free garlic (Allium sativum L.) plants obtained by thermotherapy and meristem tip culture. Journal of Phytopathology, Berlin, v.132, p. 186$192,1991$.

DODDS, J. H.; ROBERTS, L. W. Experiments in plant tissue culture. $2^{\text {nd }}$. ed. Cambridge, Estados Unidos: Cambridge University Press, 1993.

DORION, N.; KADRI, M.; BIGOT, C. In vitro preservation at low temperature of rose plantlets usable for direct acclimatization. Acta Horticulturae, Wageningen, v.298, p.291-300, 1991.

DUTILH, J.H.A. Investigações citotaxonômicas em populações brasileiras de Hippeastrum Herb. 1987, Dissertação (Mestrado em Biologia Vegetal) Campinas, UNICAMP: Instituto de Biologia,

LOEBENSTEIN, G.; LAWSON, R.H.; BRUNT, A.A. Virus and Virus-like Diseases of Bulb and flower Crops. Wiley Publisher., 1995. 543 p.

MOREL, G.; MARTIN, C. Guérison de dahlias atteints d'une maladie à virus. Comptes Rendues Hebdomadaires des Seances de l'Academie des Sciences, Paris, v.235, 1952.

MURASHIGE, T.; SKOOG, F. A revised medium for rapid growth and bioassays with tobacco tissue culture. Physiologia Plantarum, Copenhagen, v.15, p.437-497, 1962.

QUAK, F. Meristem culture and vírus free plants. In: REINERT, J. \& BAJAJ, Y.P.S., ed. Applied and fundamental aspects of plant cell, tissue and organ culture. Berlin: Springer-Verlag, 1977. p.598-618.

TOMBOLATO, A.F.C.; EGLIT, A.C.; COSTA, A.M.M. Amarílis (Hippeastrum sp.) In: TOMBOLATO, A.F.C. \& COSTA, A.M.M. Micropropagação de plantas ornamentais. Campinas: Instituto Agronômico, 1998. p.1517. (Boletim técnico, 174) 
Tabela 1. Médias das notas dos tratamentos de conservação in vitro de três cvs. de amarílis: Aple Blosson (AB), Red Lion (RL) e Orange Souvereign (OS). Instituto Agronômico (IAC), 2004.

Table1. Treatments averages in the in vitro conservation of three amaryllis cultivars: Apple Blossom (AB), Red Lion $(R L)$ and Orange Sovereign (OS). Instituto Agronômico (IAC), 2004.

\begin{tabular}{|c|c|c|c|c|c|c|}
\hline \multirow[t]{2}{*}{$\begin{array}{c}\text { TRATAMENTOS } \\
\text { Treatments }\end{array}$} & \multirow{2}{*}{$\begin{array}{c}\text { Sacarose } \\
\text { Sucrose } \\
\left(\mathrm{g} \mathrm{L}^{-1}\right)\end{array}$} & \multirow{2}{*}{$\begin{array}{c}\text { Temperatura } \\
\text { Temperature } \\
\left({ }^{\circ} \mathrm{C}\right)\end{array}$} & \multirow[t]{2}{*}{ MS* } & \multicolumn{3}{|c|}{$\begin{array}{l}\text { NOTAS } \\
\text { Grades }\end{array}$} \\
\hline & & & & $\mathrm{AB}$ & RL & OS \\
\hline 1 & 10 & 18 & 1 & 7,88 & 5,00 & 6,00 \\
\hline 2 & 10 & 25 & 1 & $\mathbf{8 , 8 8}$ & 7,60 & 7,11 \\
\hline 3 & 10 & 18 & $1 / 2$ & 5,22 & 4,55 & 4,37 \\
\hline 4 & 10 & 25 & $1 / 2$ & 6,30 & 4,66 & 4,77 \\
\hline 5 & 20 & 18 & 1 & 8,22 & 7,33 & 7,55 \\
\hline 6 & 20 & 25 & 1 & 9,66 & 9,12 & 8,50 \\
\hline 7 & 20 & 18 & $1 / 2$ & 7,55 & 6,30 & 6,66 \\
\hline 8 & 20 & 25 & $1 / 2$ & 8,11 & 7,11 & 6,87 \\
\hline 9 & 40 & 18 & 1 & 8,62 & 6,87 & 7,12 \\
\hline 10 & 40 & 25 & 1 & 9,28 & 9,57 & 9,00 \\
\hline 11 & 40 & 18 & $1 / 2$ & 6,75 & 4,88 & 5,50 \\
\hline 12 & 40 & 25 & $1 / 2$ & 7,37 & 5,50 & 6,00 \\
\hline 13 & 30 & 18 & 1 & 10,00 & 10,00 & 10,00 \\
\hline 14 & 30 & 25 & 1 & 10,00 & 10,00 & 10,00 \\
\hline
\end{tabular}

Tabela 2. Análise da variância dos tratamentos de conservação in vitro em 3 cv. de amarílis, Instituto Agronômico (IAC), 2004 Table 2. Variance analysis in the in vitro conservation treatments of three amaryllis cultivars, Instituto Agronômico (IAC), 2004.

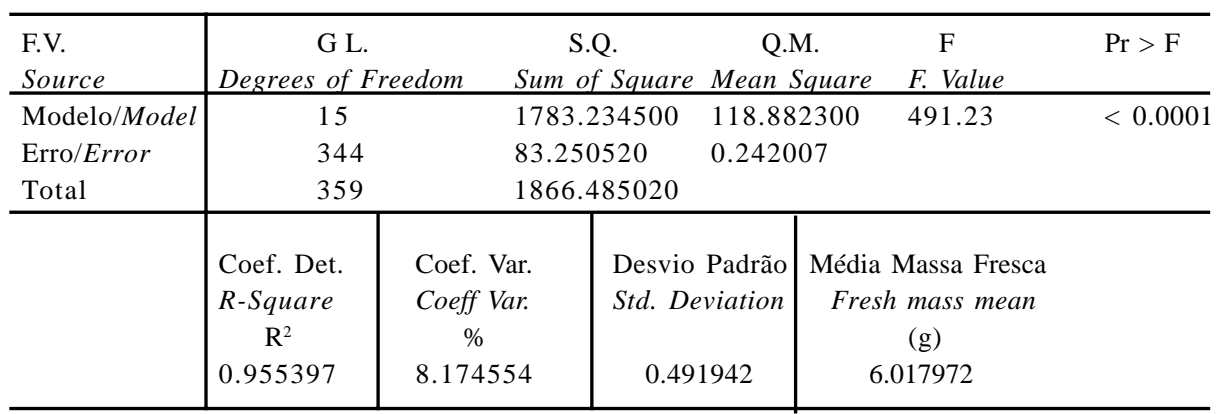

Médias por quadrados mínimos - Ajuste por Comparações Múltiplas: Tukey-Kramer Averages by minimum squares - Tukey-Kramer Multiple Comparison Procedure

\begin{tabular}{llll}
\hline Cultivar & MF LSMEAN & MF LSMEAN & \\
Apple Blossom & 6.64352507 & 1 & \\
Red Lion & 5.87586736 & 2 & \\
Orange Souvereign & 5.72823004 & 3 & \\
\hline \multicolumn{5}{l}{$\begin{array}{l}\text { Médias por quadrados mínimos para efeito de cultivar } \\
\text { Averages by minimum squares to effect cultivar }\end{array}$} \\
\hline i/j & 1 & 2 & 3 \\
Apple Blossom & & $<.0001$ & $<.0001$ \\
Red Lion & $<.0001$ & & 0.0546 \\
Orange Souvereign & $<.0001$ & 0.0546 & \\
\hline
\end{tabular}


Tabela 3. Análise fatorial da influência das variáveis fisiológicas, em $3 \mathrm{cv}$. de amarílis, na composição das médias da massa fresca (MF) dos tratamentos de 1 a 12. Instituto Agronômico (IAC), 2004

Table 3. Factorial analysis of the influence of physiological variables, in three amaryllis cultivars, on the composition of the fresh mass averages of the treatments 1 to 12. Instituto Agronômico (IAC), 2004.

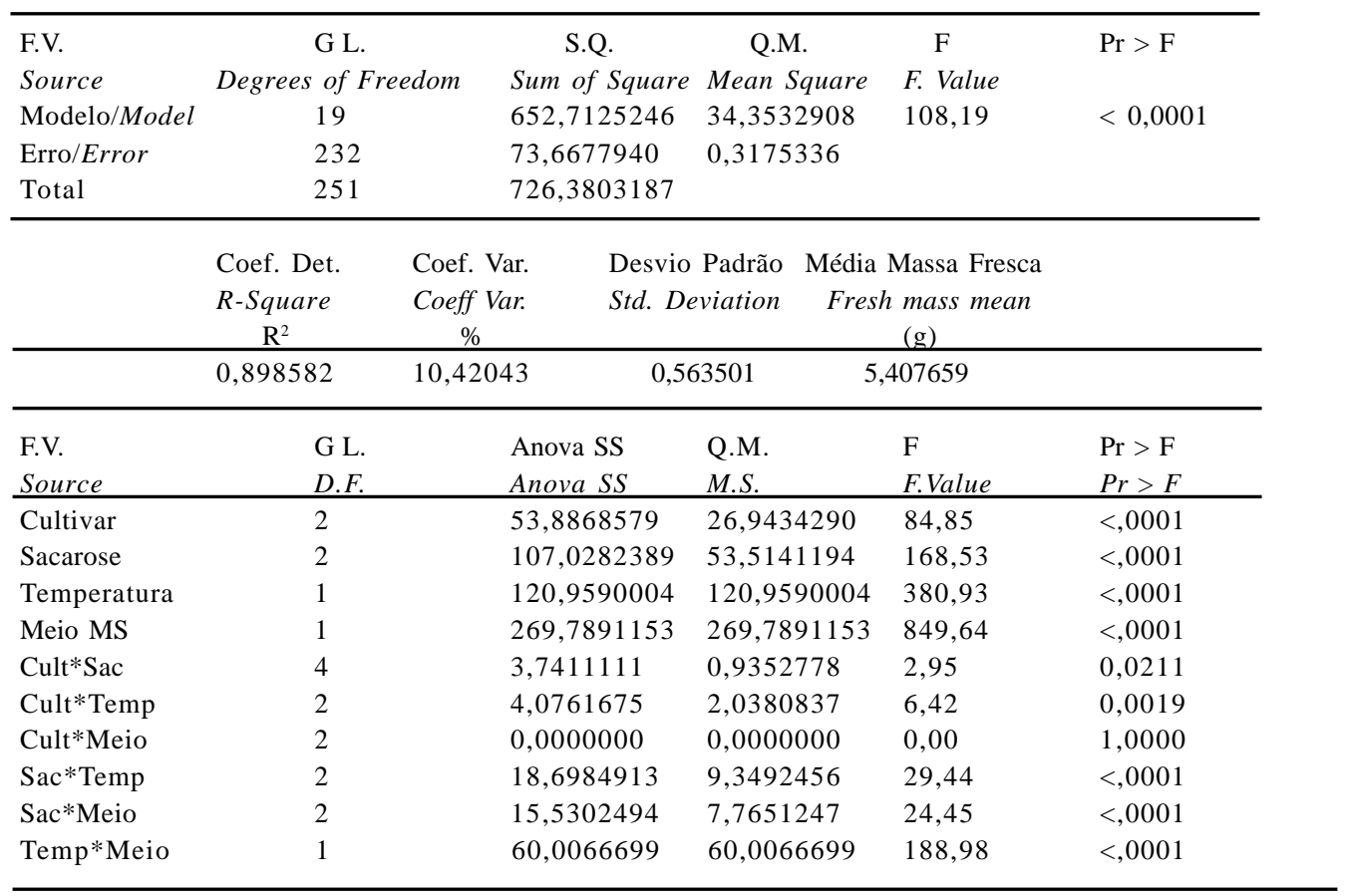

Teste t para MF cult - Médias com a mesma letra não são significativamente diferentes a $5 \%$ de probabilidade Test " $t$ " for FM cult - Averages with the same letter are not significantly different (probability=0.05)

\begin{tabular}{clll} 
Grupo t & Média & $\mathrm{N}$ & Cultivar \\
Group $t$ & Mean & $N$ & Cultivar \\
\hline A & 6,05155 & 84 & Apple Blossom \\
B & 5,18476 & 84 & Red Lion \\
C & 4,98667 & 84 & Orange Souvereign \\
\hline
\end{tabular}

Teste t para MF Sac - Médias com a mesma letra não são significativamente diferentes Test "t" for FM Suc - Averages with the same letter are not significantly different

\begin{tabular}{|c|c|c|c|}
\hline Grupo $t$ & Média & $\mathrm{N}$ & Sacarose \\
\hline Group $t$ & Mean & $N$ & Sucrose \\
\hline $\bar{A}$ & 5,91643 & 84 & 2 \\
\hline A & 5,81881 & 84 & 4 \\
\hline B & 4,48774 & 84 & 1 \\
\hline
\end{tabular}

Teste t para MF Temp - Médias com a mesma letra não são significativamente diferentes Test " $t$ " for FM Temp - Averages with the same letter are not significantly different

\begin{tabular}{|c|c|c|c|}
\hline \multirow{2}{*}{$\begin{array}{l}\text { Grupo t } \\
\text { Group } t\end{array}$} & Média & $\mathrm{N}$ & Temperatura ${ }^{\circ} \mathrm{C}$ \\
\hline & Mean & $N$ & Temperature \\
\hline $\bar{A}$ & 6,10048 & 126 & 25 \\
\hline B & 4,71484 & 126 & 18 \\
\hline
\end{tabular}

Teste t para MF Meio MS - Médias com a mesma letra não diferem significativamente Test "t" for FM MS MEDIUM - Averages with the same letter are not significantly different

\begin{tabular}{clll} 
Grupo t & Média & $\mathrm{N}$ & Meio MS \\
Group $t$ & Mean & $N$ & Medium MS \\
\hline A & 6,43417 & 127 & 1 \\
B & 4,36472 & 125 & $1 / 2$ \\
\hline
\end{tabular}


Tabela 4. Comparação das médias e desvios-padrão entre cultivares e os 14 tratamentos de conservação in vitro em três cv. de amarílis, Instituto Agronômico (IAC), 2004.

Table 4. Comparison of averages ans standard deviation among cultivars and the 14 treatments of in vitro conservation of 3 amaryllis cultivars. Instituto Agronomico (IAC), 2004.

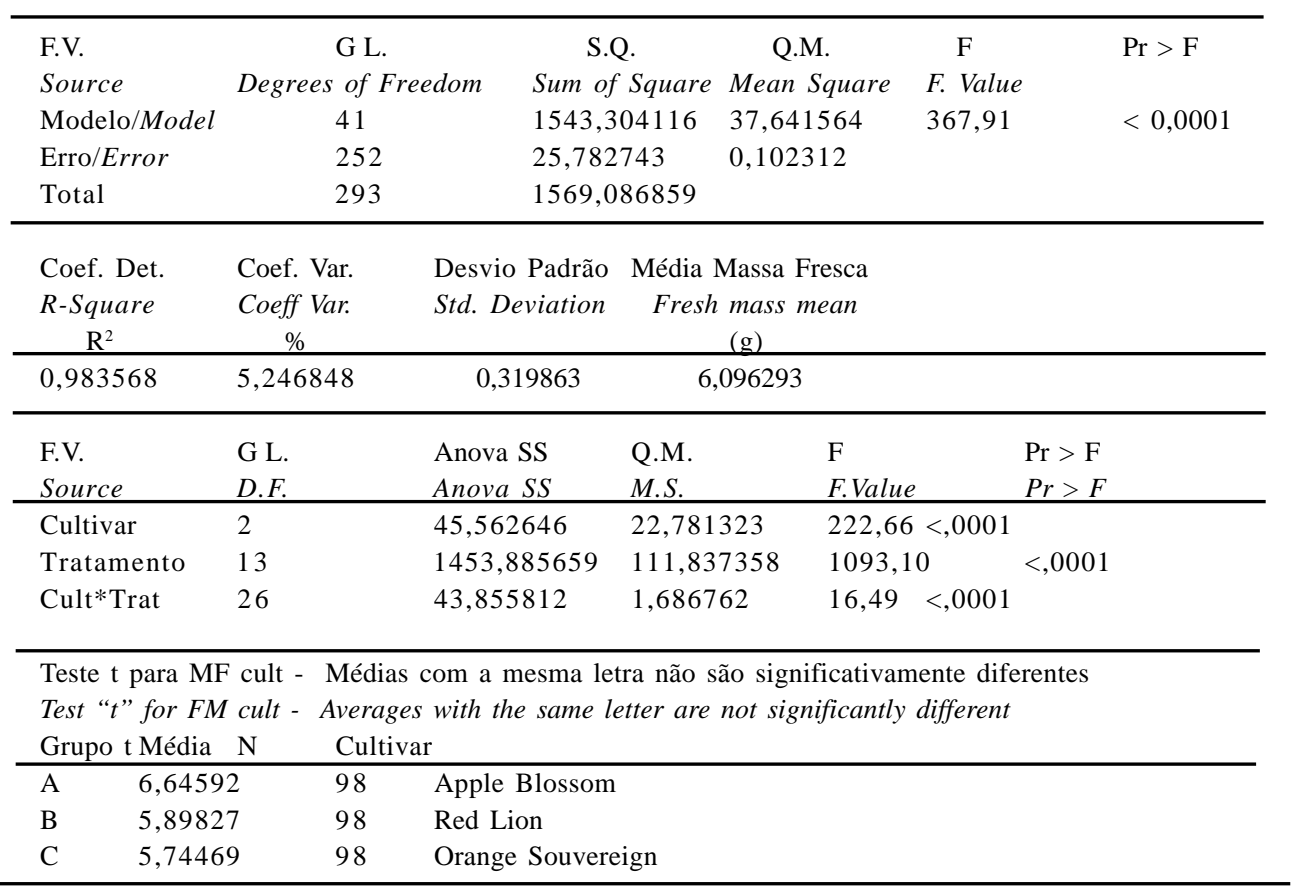

Teste t para Tratamentos (MF) - Médias com a mesma letra não são significativamente diferentes a 5\% de probabilidade Test " $t$ " for Treatments (FM) - Averages with the same letter are not significantly different (probability=0.05)

\begin{tabular}{|c|c|c|c|}
\hline \multicolumn{2}{|c|}{ Grupo t Média } & $\mathrm{N}$ & Tratamento \\
\hline A & 10,29571 & 21 & S30 T25 MS \\
\hline A & 10,16048 & 21 & S30 T18 MS \\
\hline B & 9,03238 & 21 & S40 T25 MS \\
\hline $\mathrm{C}$ & 8,15762 & 21 & $\mathrm{~S} 20 \mathrm{~T} 25 \mathrm{MS}$ \\
\hline $\mathrm{D}$ & 5,72286 & 21 & S10 T25 MS \\
\hline $\mathrm{D}$ & 5,58857 & 21 & S20 T18 MS \\
\hline $\mathrm{E}$ & 5,38143 & 21 & S40 T18 MS \\
\hline $\mathrm{F}$ & 5,15476 & 21 & S20 T18 MS \\
\hline $\mathrm{G}$ & 4,76476 & 21 & $\mathrm{~S} 20 \mathrm{~T} 18 \mathrm{MS}^{1 / 2}$ \\
\hline G & 4,76429 & 21 & S10 T18 MS \\
\hline G & 4,60619 & 21 & $\mathrm{~S} 40 \mathrm{~T} 25 \mathrm{MS} 1 / 2$ \\
\hline $\mathrm{H}$ & 4,25524 & 21 & S40 T18 $\mathrm{MS}^{1 / 2}$ \\
\hline I & 3,92905 & 21 & $\mathrm{~S} 10 \mathrm{~T} 25 \mathrm{MS} 1 / 2$ \\
\hline $\mathrm{J}$ & 3,53476 & 21 & S10 T18 MS $1 / 2$ \\
\hline
\end{tabular}

$\mathrm{S}=$ sacarose /sucrose $\left(\mathrm{g} \mathrm{L}^{-1}\right)$

$\mathrm{T}=$ temperatura $/$ temperature $\left({ }^{\circ} \mathrm{C}\right)$

MS = solução salina / nutrients solution MURASHIGE e SKOOG (1962)

MS1 12 = metade da solução salina / half of nutrients solution MURASHIGE e SKOOG (1962) 


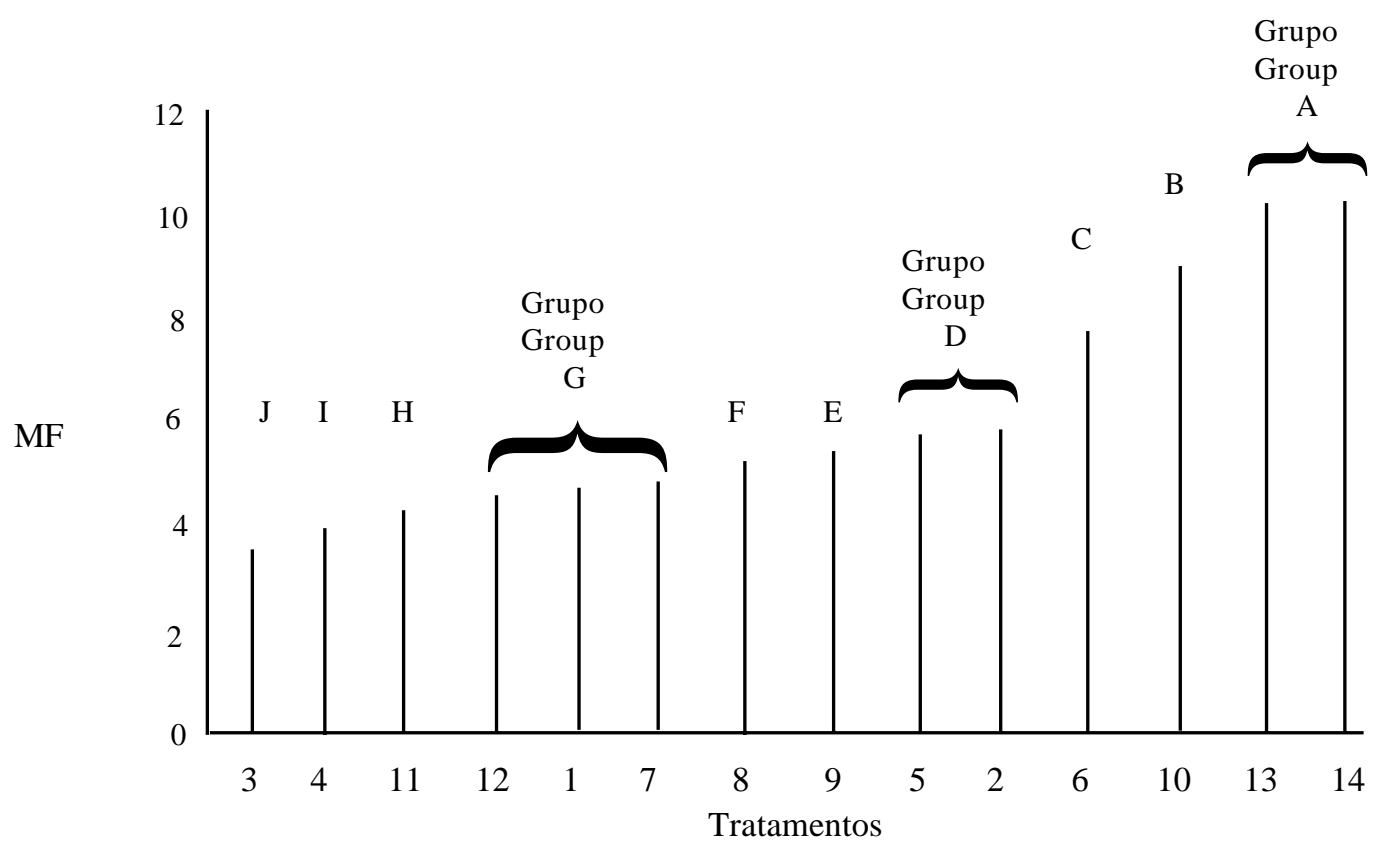

Figura 1. Grupos do teste "t" para os tratamentos de conservação in vitro em 3 cvs. de amarílis, sendo Grupo A (13 e 14), Grupo B (10), Grupo C (6), Grupo D (5 e 2), Grupo E (9), Grupo F (8), Grupo G (7, 1 e 12), Grupo H (11), Grupo I (4) e Grupo J (3); realizados no IAC, em 2004, sendo:

Figure 1. " $t$ " test groups for the in vitro conservation treatments of three amaryllis cultivars, in which Group A (13 and 14), Group B (10), Group C (6), Group D (5 and 2), Group E (9), Group F (8), Group G (7, 1 and 12), Group H (11), Group I (4) and Group $J$ (3); carried out at IAC, in 2004, in which:

\begin{tabular}{llll}
\hline $\begin{array}{l}\text { Tratamentos } \\
\text { Treatments }\end{array}$ & $\begin{array}{l}\text { Sacarose } \\
\text { Sucrose } \\
\left(\mathrm{g} \mathrm{L}^{-1}\right)\end{array}$ & $\begin{array}{l}\text { Temperatura } \\
\text { Temperature } \\
\left({ }^{\circ} \mathrm{C}\right)\end{array}$ & \begin{tabular}{l} 
MS* \\
\hline 1
\end{tabular} \\
\hline 10 & 18 & 1 \\
2 & 10 & 25 & 1 \\
3 & 10 & 18 & $1 / 2$ \\
4 & 10 & 25 & $1 / 2$ \\
5 & 20 & 18 & 1 \\
6 & 20 & 25 & 1 \\
7 & 20 & 18 & $1 / 2$ \\
8 & 20 & 25 & $1 / 2$ \\
9 & 40 & 18 & 1 \\
10 & 40 & 25 & 1 \\
11 & 40 & 18 & $1 / 2$ \\
12 & 40 & 25 & $1 / 2$ \\
13 & 30 & 18 & 1 \\
14 & 30 & 25 & 1 \\
\hline
\end{tabular}

* $1=100 \%$ e $1 \frac{1}{2}=50 \%$ da solução salina MS (Murashige e Skoog,1962)

* $1=100 \%$ e $1 / 2=50 \%$ of MS nutrients solution (Murashige \& Skoog, 1962). 